\title{
JUVENTUDE E CELULAR: A BATALHA DAS MÍ- DIAS SOCIAIS NA FRONTEIRA
}

CRISTOVÃO DOMINGOS ALMEIDA

Universidade Federal do Pampa, São Borja, Ro Grande do Sul, Brasil

e-mail: cristovaoalmeida@gmail.com

ANELICE BELMONTE

Universidade Federal do Pampa, São Borja, Ro Grande do Sul, Brasil e-mail: anelice.belmonte@hotmail.com

RONALDO COLVERO

Universidade Federal do Pampa, São Borja, Ro Grande do Sul, Brasil e-mail: rbcolvero@gmail.com 
JUVENTUDE E CELULAR: A BATALHA DAS MÍDIAS SOCIAIS NA FRONTEIRA

Resumo: O propósito deste artigo é compreender como os jovens que vivem na fronteira oeste do Rio Grande do Sul consomem as mídias sociais. Consideramos que as mídias sociais é uma das mais importantes fontes de informação, inteiração e entretenimento entre os jovens, por isso, utilizamos os conceitos de convergência (JENKINS, 2008) para revelar a "caixa preta" do consumo de mídias sociais entre a juventude. Metodologicamente, a pesquisa é qualitativa e de inspiração etnográfica, com a utilização das técnicas de observação e entrevista em profundidade para obter as informações. Evidenciamos que a juventude reivindica, cada vez mais, os meios de comunicação mais rápidos, práticos e eficazes, para estar conectados e interagindo com as pessoas em tempo real. Palavras-Chave: Mídias Digitais; Celular; Juventude.

\section{JUVENTUD Y MÓVIL : LA BATALLA DE LOS MEDIOS SOCIALES EN LA FRONTERA}

Resumen: El propósito de este artículo es entender cómo la gente joven que vive en la frontera occidental de Río Grande do Sul consumir medios de comunicación social. Creemos que los medios sociales son una de las fuentes más importantes de información, la complementariedad y el entretenimiento entre los jóvenes, por lo que utilizamos los conceptos de convergencia (JENKINS, 2008) para revelar el "recuadro negro" de consumo de medios de comunicación social entre los jóvenes. Metodológicamente, la investigación es la inspiración cualitativa y etnográfica, con el uso de técnicas de observación y entrevista en profundidad para obtener la información. Se demuestra que las reclamaciones de jóvenes, cada vez más, los medios más rápidos, prácticos y eficaces de comunicación, al ser conectados e interactuar con personas en tiempo real. Palabras Chave: Medios Digitales; celular; Juventud.

\section{YOUTH AND MOBILE: THE BATTLE OF SOCIAL MEDIA ON THE BOR- DER}

Abstract: The purpose of this article is to understand how young people living on the western border of Rio Grande do Sul consume social media. We believe that social media is one of the most important sources of information, complementary nature and entertainment among young people, 
so we use the convergence concepts (JENKINS, 2008) to reveal the "black box" of social media consumption among youth. Methodologically, the research is qualitative and ethnographic inspiration, with the use of observation techniques and in-depth interview to get the information. We show that youth claims, increasingly, the fastest, practical and effective means of communication, to be connected and interacting with people in real time. Keywords: Digital Media; cell phone; Youth. 


\section{INTRODUÇÃO}

A mídia é considerada o quarto maior segmento econômico do mundo, sendo a maior fonte de informação e entretenimento que a população possui (RAMONET, 2002). A mesma se destaca como instrumento fundamental nesses setores, obtendo uma dimensão capital e central nos diversos âmbitos da sociedade moderna. A política, o esporte, a escola, a economia são atravessados e marcados pela influência dos meios de comunicação de massa.

Devido aos avanços tecnológicos que fazem com que as informações veiculem de forma rápida e real, o domínio da mídia cresce de forma exacerbada, e isso se dá pelo fato de que há uma demanda por parte de vários públicos e faixa etária. Ainda que predominante no meio digital, não se pode afirmar com total certeza que apenas a 'geração digital' se utiliza desse espaço, ao presenciar diversas tecnologias de fácil acesso, pois a interação e o consumo de mídias ocorrem a partir da vontade das pessoas interagirem através dessas plataformas e entenderem o seu funcionamento. Ainda assim, é notório que os jovens por já crescerem inseridos em um ambiente tecnológico dinâmico, prático e atrativo tornam-se os maiores consumidores de mídia.

A juventude tem, desde cedo, ao seu dispor as plataformas convencionais como rádio, TV e Jornais impressos, e também os computadores e os celulares mais atuais e sofisticados, que dispõem de diversas utilidades, disponibilizando o alcance de informações de qualquer lugar do mundo.

Na realidade do município de São Borja/RS, podemos notar o consumo de mídia por boa parte da população. As pessoas têm acesso as mídias tradicionais como rádio e tv, até as mais atuais, principalmente, o acesso gratuito à internet nas praças e no Cais do Porto, locais de maior aglomeração social. Além disso, a cidade está se reconfigurando devido a migração de jovens para cursar um ensino superior na cidade. Essa reorganização social influencia diretamente nas novas perspectivas de uso, consumo e apropriação das mídias na cidade fronteiriça. Diante disso, analisaremos questões específicas a partir do uso do celular com o intuito de compreender as interações entre os jovens a partir do consumo de mídia, considerando que as tecnologias da informação podem ser estruturadas de forma positiva e estratégica para ampliar e fortalecer a comunicação interpessoal. 


\section{MídIAS X CONSUMO, A PRESENÇA DA CHAMADA GERAÇÃo DIGITAL}

As mídias sociais estão cada vez mais presentes na sociedade em que vivemos. Seja na zona rural ou urbana, no bairro ou favela, nos empreendimentos empresariais, nas residências da classe alta, média e baixa. As mídias sociais são realidades nesses espaços, pois, mostram-se rápidas, eficazes e nos torna assíduos das tecnologias avançadas e indispensáveis na atualidade. Nesse contexto, as mídias sociais podem ser reconhecidas como veículos que expressam a integração sociocultural entre as pessoas, pois:

[...] agem como o dispositivo mais poderoso na dissolução de um horizonte cultural comum no âmbito da nação ao encarnarem como uma mediadora na construção de outras identidades: das cidades, das regiões, do espaço local, etc... (ESCOSTEGUY, 2001, p.163).

A cada dia surgem novos aparatos tecnológicos e embora muitos não cheguem a ser difundidos ao grande público -, desde que a internet passou a se popularizar no final da década de 1990 -, eles modificaram-se, aperfeiçoam-se e se adequam, de modo que alguns conceitos já foram incorporados ao cotidiano das pessoas. Eisenstein e Stefenon (2009) discutem a facilidade que os jovens têm para lidar com essas ferramentas e novos meios de comunicação tecnológicos e apontam a alta velocidade dessa ocorrência em tempo real.

\footnotetext{
O mundo virtual vai, progressivamente, confundindo os seus limites com o mundo real no cotidiano de crianças e adolescentes. A internet, o telefone celular e muitos novos equipamentos de tecnologia da informação vão transformando os Comportamentos e as formas de se relacionar com a família, com os amigos e com as novas possibilidades de viajar pelo mundo sem sair de casa. (ElSENSTEIN; STEFENON, 2009, p.1)
}

Em 2011, o Instituto Brasileiro de Geografia e Estatística (IBGE)45 apontou que 77,7 milhões de pessoas de dez anos ou mais de idade declararam ter utilizado a internet nos três meses anteriores à data da entrevista, o que mostrava que se houve um crescimento de $14,7 \%$ da faixa da população brasileira com acesso à rede mundial de computadores em relação a 2009, re- 


\section{JUVENTUDE E CELULAR: A BATALHA DAS MÍDIAS SO- CIAIS NA FRONTEIRA}

presentando acréscimo de 9,9 milhões de pessoas. O Instituto identificou ainda que os bens duráveis, tais como: TV, computador, celular; podem ter sido os maiores contribuintes para tais números. Insere-se a essa realidade, o ingresso das classes populares para o universo online como um dado que deve manter o ritmo de crescimento de usuários residenciais, bem como lan house ${ }^{46}$.

Já em 2012, a InteractiveAdvertising Bureau47 (IAB Brasil), realizou uma pesquisa onde declarou que mais de $40 \%$ dos entrevistados passam pelo menos duas horas diárias online, enquanto $25 \%$ acessam a Internet ao mesmo tempo em que assistem à TV. Isso mostra que o forte uso de tais meios de mídias pela sociedade, é simultaneamente. Os dados mostram que o consumo de mídia é uma tendência entre os jovens e adultos e, mais, nos revelam que a internet é o que mais cresce e tem preferência entre os entrevistados, independente de faixa etária. Essas informações nos ajudam a compreender o cenário de consumo a partir das ferramentas tecnológicas, pois, o consumo pode reconfigurar o contato e a aproximação com Outro. Entendemos consumo, neste estudo, a partir dos argumentos de Baccega (2008, p. 120),

[...] o consumo é analisado desde sua condição estruturante, como dinâmica sensível e formatadora de uma ampla cultura comunicacional. Consumir nesse caso, é muito mais do que mero exercício de gostos, caprichos ou compras irrefletidas, mas todo um conjunto de processos e fenômenos socioculturais complexos, mutáveis, através dos quais se realizam a apropriação e os diferentes usos de serviços e produtos.

O que facilitou em grande parte essas alterações na forma de comunicação são as novas tecnologias disponíveis e de fácil alcance ao grande público, como o telefone celular, cada vez mais acessível a todos os estratos sociais, e sendo assim, a facilidade da inserção de jovens no ambiente cibernético. Para entendermos melhor esse meio, tomamos o conceito de juventude por ALMEIDA e FEITOSA (2010, p. 102):

46 Loja ou local de entretenimento caracterizado por ter diversos computadores de última geração conectados em rede de modo a permitir a interação de dezenas de jogadores. Dicionário informal, consulta em 05/12/2014 ; http://www.dicionarioinformal.com. br/significado/lan\%2ohouse/2845/

47 http://iabbrasil.net/portal/ 
A ideia de condição juvenil remete, em primeiro plano, a uma etapa do ciclo de vida, de ligação ou transição como diz a noção clássica, entre a infância, época de dependência e necessidade de proteção, para a idade adulta, o ápice do desenvolvimento que, em nossa sociedade, está relacionado a tornar-se capaz de exercer atividades produtivas, de reprodução e de participação social.

É importante salientar que a participação social da juventude se associa e se potencializa através das ferramentas comunicacionais. Se por um lado elas engendram suspeitas, medos, discriminações e violências ao fortalecer estereótipos, por outro lado fomentam interações entre grupos e podem aproximar as pessoas do discurso público. Essas posturas e hábitos introduzidos a partir das mídias digitais, como argumenta Santaella (2003, p. 82) "não foram tão abruptos como alguns podem pensar". Essas ocorrências foram sendo introduzidas gradativamente na mídia digital, a partir da sua interatividade, uma vez que, ela promove maior diversidade, liberdade e possibilita que as pessoas se comportem como "produtor, criador, compositor, montador, apresentador, difusor de seus próprios produtos" (SANTAELLA, 2003, p. 82).

\section{A CIDADE DE SÃO BORJA, TERRITÓRIO E ECONOMIA}

As cidades de fronteira apesar do distanciamento das capitais, e ainda que muitas se mostrem carentes em suas estruturas para mercado de atacado, tem um papel crucial por serem consideradas como suas 'portas' de entrada do país.

Segundo a Lei 6.634/79, a faixa de fronteira é considerada área indispensável à segurança nacional e corresponde aos $150 \mathrm{~km}$ de extensão, paralelos à linha divisória terrestre do Brasil com dez países da América do Sul. Na faixa de fronteira é vedada, sem o prévio assentimento do órgão federal competente, a prática dos atos referentes à concessão de terras, abertura de vias de transportes e instalação de meios de comunicação; construção de pontes; estradas internacionais e campos de pouso; estabelecimentos ou exploração de indústrias que interessem a segurança nacional. (CARNEIRO, 2012, p. 5)

São Borja é uma das cidades do Estado do Rio Grande do Sul, contempladas pelo alto reconhecimento de toda a sua diversidade histórico-cultural. No dia 10 de outubro de 1994, o governador do Estado do Rio Grande do Sul 


\section{JUVENTUDE E CELULAR: A BATALHA DAS MÍDIAS SO- CIAIS NA FRONTEIRA}

declarou "São Borja, como uma Cidade Histórica", conforme o artigo 82, inciso V da Constituição do Estado do Rio Grande do Sul. Em 13 de outubro de 1817, com a denominação de São Francisco de Borja e instalado a 21 de abril de 1834, foi criado o Alvará do município que conta com uma população estimada em mais de 60 mil habitantes em seus 3.616,019 km² de território.

Sua economia está baseada, principalmente, na agricultura com a produção de grãos como soja, trigo, milho; sendo o arroz, a principal fonte econômica do município. Na pecuária com a criação de bovinos de corte e leite e de ovinos. Comercialmente próspero devido sua localização estratégica que permite o fácil intercâmbio com países da América Latina. Muitos desses dados apresentados também na obra "Faixa de fronteira do Rio Grande do Sul: economia, infraestrutura e gestão do território" por Camilo Carneiro, Gabriel Sevilla e Róber Avila, demostra a relevância comercial da região atentando para a formação sociocultural e acadêmica desse meio:

Em um mundo em transformação, comandado pelas técnicas e pela expansão da economia global, os municípios da faixa de fronteira gaúcha precisam investir em conhecimento, formação técnica e qualificação de sua população. Só assim evitarão uma situação de estagnação e ostracismo. (CARNEIRO, 2012, p. 22)

O município tem apresentado um grande crescimento econômico e populacional (IBGE, 2010). Principalmente, depois da implantação de duas instituições de nível superior no município: a Universidade Federal do Pampa e o Instituto Federal Farroupilha. Tais instituições alavancaram uma maior porcentagem de jovens na cidade, oriundos de várias partes do país, trazendo consigo peculiaridades de suas regiões em relação ao consumo de mídias eletrônicas e até mesmo, influenciando no consumo, e movimentando a moeda local.

As iniciativas de universidades (...) que visam o desenvolvimento de projetos na faixa de fronteira gaúcha, são de suma importância, haja vista que a maioria das universidades localizadas nos municípios de fronteira é de implantação recente e possui um número limitado de cursos. Todavia esses campi são fundamentais para a fixação da população jovem em seus municípios de origem, bem como para a formação de quadros técnicos necessários ao desenvolvimento da economia da região. (CARNEIRO, 2012, p. 23)

A comunidade diversificada de culturas que se encontra na cidade ofe- 
rece a esses imigrantes sua cultural local, pois "um mundo que parece dominado por um repertório cultural global, novas comunidades e identidades estão sendo constantemente construídas e reconstruídas" (ESCOSTEGUY, 2004, p. 147). E este fenômeno tende a reconfigurar o modo de vida das pessoas ao trazer à região novas práticas, comportamentos, informações e conhecimentos, que transformam não só o sentido de vida de seus habitantes, mas, consequentemente, o cenário da região de fronteira como um todo.

\section{O Celular e a falácia da CAixa preta de JenKins}

A geração digital clama por meios de comunicação mais rápidos, práticos e eficazes, onde possam estar conectados e interagindo com o mundo todo em tempo real. Apesar de muitos notebooks e tablets se apresentarem atuais e utilitários, o comodismo não os permite levá-los para todas as atividades cotidianas, e é a partir dessa perspectiva de facilidades em locomoção que indústrias telefônicas criam aparelhos que tem servido como verdadeiras 'caixas pretas' (JENKINS) do ser humano.

Boa parte do discurso contemporâneo sobre convergência começa e termina com o que chamo de Falácia da Caixa Preta. Mais cedo ou mais tarde, diz a falácia, todos os conteúdos midiáticos irão fluir por uma única caixa preta em nossa sala de estar (ou, no cenário dos celulares, através de caixas pretas que carregamos conosco para todo lugar). (JENKINS, 2008, p.42)

É difícil encontrar atualmente indivíduos que não dispõem de pelo menos um aparelho celular, por mais simples que seja o seu aparelho. Nesse sentido, o celular passou de mero meio de comunicação por voz em tempo real, para ferramenta de comunicação avançada e abrangente, além de suas diversas utilidades como câmeras, ferramentas de acesso à internet, transmissores de tv, entre outras, ainda possuem aplicativos para as mais diversas funções, entre eles, jogos e entretenimento. A maioria dos aplicativos foi inventada para suprir demandas que surgem conforme as necessidades de seus usuários.

Com o desenvolvimento da telefonia celular e das possibilidades de conexão com a internet, as pessoas passaram a se comunicar em movimento; elas recebem e enviam e-mails e SMS dos celulares. Tiram fotos e gravam vídeos com esses aparelhos e enviam para sua rede ou para sites como o YouTube, sem precisar parar o que estão fazendo. (TELLES, 2009, p.77) 
Ou seja, todos os usuários de celular, que corresponde a 19\% da população entre 18 e 24 anos do Rio Grande do Sul segundo o IBGE (2012), tem uma 'caixa preta' onde são guardados arquivos, contatos, fotos entre outras informações pessoais e de interesse dos mesmos. E é a partir desses dados que o celular com todos os seus canais de mídia foi a ferramenta de consumo escolhida para observação nesse eixo da sociedade, onde "estilos de vida manifestam-se através de práticas, hábitos e signos que a cultura midiática veicula (...) do consumo e para o consumo", afirma Baccega (2009, p.140).

\section{ENTRADA EM CAMPO E O 'MERGULHO' DO PESQUISADOR}

Esta pesquisa tem inspiração etnográfica, uma vez que buscamos compreender, durante quatro meses, as manifestações dos jovens de São Borja em relação ao consumo de mídias. Segundo Duarte (2011) o pesquisador ao se utilizar dos princípios etnográficos como método de trabalho, precisa dispor de tempo e preparo além de um breve conhecimento documental do objeto a ser analisado, pois esse método é tido como "um método de pesquisa qualitativa e empírica que apresenta características específicas” (2011. p. 4), exigindo assim o máximo de dedicação e envolvimento por parte do pesquisador.

Partimos do pressuposto de que o apresentado por inúmeros estudiosos a respeito do mundo dos jovens traz informações relevantes. No entanto, acreditamos que os perfis dos jovens, distantes dos grandes centros urbanos, focos das pesquisas de mercado, são quase desconhecidos. Pesquisas qualitativas sobre essas gerações na fronteira oeste do Rio Grande do Sul precisam ser ampliadas. Duarte (2011) ainda defende que, assim como as pesquisas qualitativas, as de inspiração etnográfica passam por algumas etapas crucias para a excelência de seu funcionamento:

Retomando nosso caminho pela etnografia, a primeira etapa é o levantamento bibliográfico e a leitura do material coletado. A segunda etapa é a elaboração de um diário ou caderno de campo. Este caderno terá um papel fundamental. Nele o pesquisador anotará as questões que o levaram a escolher aquele grupo e aquele tema, e as perguntas que tem em mente sobre o assunto. Assim, o caderno funcionará como um registro descritivo de tudo o que ele vir e presenciar, seja em uma aldeia de índios bororo, seja em uma redação de um grande jornal. A terceira etapa, se podemos assim nomeá-la, é a entrada no "campo". Trata-se da inserção do 
pesquisador no grupo. E aí encontraremos uma infinidade de possibilidades e variáveis que na realidade estão mais relacionadas ao universo pesquisado do que ao método propriamente dito. (DUARTE, 2011, p. 5).

Acertadas as definições de pesquisa de cunho etnográfica trazida por Duarte, decidimos tomá-lo como base para sustentar os nossos esforços na obtenção das informações, com levantamento de dados e observação e a utilização de caderno de campo e questionário para aprofundar e revelar informações que necessitam de maior esclarecimento.

\section{A ENTRADA EM CAMPO}

Para que pudéssemos compreender o meio social dos jovens, realizou-se antes da entrada em campo um mapeamento dos locais públicos com maior fluxo de utilização dos meios digitais, a fim de observá-los convivendo com indivíduos da sua idade, e demais pessoas de diferentes faixas etárias, e assim analisarmos como o mesmo se portava em sociedade. Os diários de campo foram confeccionados nos meses de outubro e novembro de 2014, sendo apenas as abordagens e acompanhamento no mês de novembro. A observação se iniciou com uma média de cinco visitas na semana ao local e em horários distintos, para que a pesquisa não fosse mais abrangente ao tipo de indivíduo que transite no local em todos os horários.

O parque General Vargas antes de se tornar um espaço de público era um estádio municipal, iniciado suas reformas em 2010 e que se mantem em processo contínuo, situa-se no centro da cidade, o que facilita o acesso das pessoas ao local, que o buscam para lazer, entretenimento e trabalho, uma vez que no local é organizado diversas feiras, existem vendedores ambulantes e as pessoas também têm acesso gratuito a internet. A sua estrutura abrange tanto as arquibancadas do antigo estádio quanto o gramado que envolve muitos desses espaços é ocupado no final da tarde por famílias, grupos de amigos, esportistas e demais pessoas que buscam no local um espaço para conversação, descanso, diversão e lazer.

\section{O MERGULHO DO PESQUISADOR}

Após algum tempo de observação, partiu-se para uma maior abrangência da segunda etapa apresentada por Duarte (2011), além dos diários de 
campo passamos a abordagem dos indivíduos. Foram aplicados 10 questionários com perguntas fechadas, para que pudéssemos ter uma visão geral desse meio, e também para que pudessem servir posteriormente como auxílio nas entrevistas em profundidade. Foram escolhidos 5 pessoas do sexo feminino e 5 do masculino na idade de 18 a 24 anos. A grande maioria com renda de 2 à 4 salários mínimos, sendo que 6 estavam cursando ensino superior, 2 tinham apenas o ensino médio completo, um em curso de graduação e outro que havia concluído o ensino superior. Nos quais se dividiam em $90 \%$ usuários de plano pré-pago ${ }^{48}$ e 10\% no plano pós-pago, tendo a fatura quitada pelos pais.

Quando questionados em relação a que serviços os mesmos utilizavam no celular as ligações e uso da internet predomina entre os favoritos, mantendo uma grande margem de distância à usualidade de serviços como troca de mensagens, dispositivos de calendário, despertador e demais ferramentas de um celular comum. A unanimidade na preferência da escolha de que canal é mais utilizado não foi nenhuma surpresa, o facebook predominou em todas as respostas, sendo seguido pelo youtube e twitter. TV e rádio só foram usados por um dos entrevistados, residente na região do interior do município onde os canais televisivos não chegam tão facilmente.

Ao questionarmos sobre a usualidade dos canais de mídias de seus dispositivos, apenas 1 dos entrevistados não utiliza o celular para se comunicar com familiares e amigos, os quesitos de informações, notícias e entretenimento são usados por 7 dos 10 entrevistados, e apenas 6 utilizam os canais para o trabalho. Entretanto, apesar de todos concordarem com a falácia da caixa preta de Jenkins quando explicada a eles, e $70 \%$ passarem de 7 à $12 \mathrm{~h}$ usando o celular, metade dos entrevistados respondeu que conseguiria ficar sem seu dispositivos por mais de 2 dias.

\section{O CELULAR: CHEGANDo À CAIXA PRETA DO JOVEM FRONTEIRIÇO}

O aparelho celular muitas vezes pode revelar muitas informações sobre seu proprietário. Mostra desde um pouco sobre o poder aquisitivo dele e sobre sua personalidade, pois muitos reportam ao aparelho de forma que

48 Pós pago: quando se assume valor mensal de assinatura / Pré-pago: quando se credita um determinado valor do qual serão debitados os serviços e as ligações efetuadas. Fonte: http://www.procon.sp.gov.br/texto.asp?id=691 
customizam os mesmos com capas, chaveiros entre outras excentricidades próprias para celular de sua preferência. Com os jovens é mais expressiva essa transfusão de personalidade para o aparelho, em vista de que o mesmo se tornou uma extensão de si próprio, e, portanto tem muito a dizer sobre:

Frente a esses resultados, percebe-se então que o telefone celular é altamente valorizado pelos jovens brasileiros em função do que ele representa. Usa-se o aparelho para uma comunicação que extrapola o sentido clássico de proporcionar o exercício da sociabilidade. Isso porque a posse de um celular comunica um estilo de vida, um recurso de entretenimento, uma busca por pertencimento e uma forma do jovem se inserir no mundo. (VERZA, 2008, p. 47)

O aparelho se tornou 'o jovem', como se o fone de ouvido, utensílio indispensável, criasse um verdadeiro cordão umbilical do indivíduo com seu ‘filho', pois através do aparelho e da relação globalizada que ele proporciona se descobrem preferências, gostos, e até mesmo sua própria identidade.

No que se refere a outros aspectos psicossociais, o celular tem tido lugar no processo de construção da identidade do jovem na medida que se instala como um objeto de desejo e adquire um valor subjetivo legitimado pela cultura do consumo. Seu uso na juventude está associado, além da busca por segurança, também ao exercício da autonomia, à vivência da privacidade e a alternativas de entretenimento. Nesse sentido ele incrementa a sensação de pertencimento ao grupo e oferece ao jovem um diferente status frente à sociedade, em função da sua representação social. (VERZA, 2008, p. 57).

Essa busca por identidade, entendimento e aceitação pela sociedade e o meio em que os mesmos habitam, é totalmente refletida nas ações que os jovens tomam e como se relacionam com os demais em seus aparelhos móveis.

Os dados coletados durante a aplicação dos questionários apenas reforçaram o perfil dos jovens nos quais realizamos o acompanhamento e análise em profundidade, ainda que um dos três acompanhados tenha se destoado dos demais, agregando à pesquisa peculiaridades sobre esse eixo da própria sociedade jovem da Fronteira Oeste, todos os três mantiveram proximidade com o pesquisador, com encontros e conversas constantes, pelo celular. 


\title{
JUVENTUDE E CELULAR: A BATALHA DAS MÍDIAS SO- CIAIS NA FRONTEIRA
}

Ana Júlia ${ }^{49}$, mineira, 21 anos, branca, classe média, espírita. A mesma reside no município desde 2011, quando ingressou na Universidade para realizar o curso de Jornalismo no qual se forma em 2015. A entrevista foi realizada na biblioteca da universidade -, em meio ao confortável ambiente gelado que o ar condicionado proporciona, o que ocasionou o arrastar da entrevista por horas -, pois como ela reside em um pensionato católico que cede quartos para estudantes na cidade, e no local não são permitidas visitas.

$O$ encontro se deu na universidade também pelo fato de ser o local de estágio da entrevistada, foram então realizadas uma série de perguntas de como se dava o consumo de mídias e preferências, e, ao final da entrevista, pedimos para ela traçar o relacionamento com seu aparelho e o que ele significa para a entrevistada.

Começa a entrevista, indagamos se a mesma preferia desligar o celular e obtive a seguinte resposta em meio a um riso nervoso:

Não posso desligar, preciso ficar ligada na hora para voltar desse intervalo, e minhas colegas ficaram de me avisar quando saíssem da sala para me dar a chave porque logo vão pra casa.

\section{Preferência pelo Facebook}

\begin{abstract}
Ah, eu uso bastante o celular pra se comunicar mesmo, mais com o pessoal de Minas, família e amigos, é muito complicado pra gente que vem de fora ficar longe dos pais e essa é uma maneira de se manter mais próximo, porque assim como eu minha mãe também ta sempre com o celular e saber disso traz uma certa segurança, com os amigos daqui eu falo mais pessoalmente porque a gente ta sempre pela universidade, mas quando eu vou pra casa eu volto a falar com todos em igual e mais pelo celular também, porque tento fazer o uso do computador mais pra estudar, então evito usar as redes nele porque dae me concentro mais, mas não desligo o celular (nesse trecho a entrevistada riu diante sua estratégia falha de concentração, segundo ela).
\end{abstract}

Também queríamos saber sobre a sua relação com as mídias Tradicionais, para entender o consumo da mídia digitais. A entrevistada disse,

[...] penso muito no futuro e a minha profissão me exige estar

49 Por questões éticas, optou-se pelo sigilo do nome. 
sempre ligada no que tá acontecendo, eu vejo vídeos, acompanho páginas e blogs do meu interesse já visando isso, mas com tantas opções eu uso tanto pra trabalho quanto pra entretenimento. No youtube, twitter, instagram eu uso mais como lazer mesmo, até porque meus amigos também tem conta neles então a gente pode falar e mostrar coisas que é de interesse comum além de só o que agente gosta. Em todos esses canais eu uso pra ver coisas relacionadas ao trabalho mas me divirto também, não tem como fazer um sem fazer o outro porque essas redes proporcionam os dois, entre outras coisas que a gente vai descobrindo com o tempo. Como eu já disse antes, eu tento me informar por outras plataformas, dae nem faço uso dessas mais convencionais, as vezes se eu to conversando com alguém nele e a pessoa comenta algo sobre a tv, olho mas pra checar sobre o assunto e rádio eu nunca ouço mesmo, até porque monto minhas listas com minhas músicas preferidas e ouço isso quando quero ouvir música.

\section{A constatação de que o celular é uma caixa preta}

[...] Ele é meu filho (risos), se eu fico sem ele eu morro eu acho (mais risos). Mas sério, como eu disse pra gente que mora longe da casa dos pais ele é mais que um aparelho de ligação, é um laço que liga a gente porque faz com que eu esteja com meus pais 24 horas por dia. E tipo, ele é minha fonte pro mundo, é nele e através dos canais que eu já disse antes que vejo o mundo e fico sabendo de tudo que preciso e quero saber, mesmo que sejam bobagens pra outras pessoas, meu celular é meu tudo, eu cuido dele e em troca ele me deixa por dentro das coisas que eu gosto, perto dos meus amigos e família, além de guardar todas as minhas coisas como foto, música e até minhas senhas que eu sempre esqueço (risos).

O celular da entrevistada era um IPhone 3 , no qual se encontrava envolto em uma capa que fazia alusão à bandeira dos Estados Unidos, semelhante a um bottón que a mesma portava em sua mochila cor vinho, o que confirma a sua classe social, pois a aquisição de tais produtos requer recursos, sendo ela, única entrevistada a ser independente financeiramente dos pais. Ao terminar a entrevista a mesma recolheu seus pertences e se recolheu ao trabalho, subindo distraidamente enquanto jogava no celular. Ana Julia correspondeu a $70 \%$ dos jovens observados na segunda etapa da pesquisa, que prezavam pelas mídias para se informar e se comunicar com a sociedade.

Outro entrevistado é o Thiago, gaúcho, 19 anos, pardo, classe média, católico não praticante. Ele concluiu o ensino médio em 2013, e aguarda sua 


\section{JUVENTUDE E CELULAR: A BATALHA DAS MÍDIAS SO- CIAIS NA FRONTEIRA}

apresentação ao serviço militar esse ano, ainda assim o mesmo prestou vestibular para Agroindústria no Instituto Federal Farroupilha na cidade de Alegrete. O mesmo reside atualmente no distrito de Samburá, região do interior de São Borja onde a sua família possui uma pequena chácara e vivem da criação do gado e dos produtos alimentícios.

A entrevista foi realizada na casa do entrevistado, durante o encontro informal de famílias e conhecidos, nos encontramos no sítio da família. Com pinheiros na estrada principal de acesso a casa, onde na sala se encontravam artefatos de porcelana e crochê, uma herança cultural a serem apreciadas. Sentei-me no sofá coberto por uma colcha de retalhos, provavelmente feita à mão, encostei os meus pés sobre o piso queimado da sala e comecei a entrevista.

A entrevista seguiu a mesma linha da anterior e com os questionamentos de como se davam as interações através das mídias, as mais usuais e o porquê dessa preferência. Também perguntei se o mesmo preferia desligar o celular, a fim de não atrapalharmos durante o processo, o mesmo afirmou que não e indaguei se poderia continuar jogando durante a entrevista, respondi que sim e continuei com mais indagações.

Eu uso mais pra sms e internet mesmo, porque como a minha namorada não tem internet dae falo com ela só por mensagem e se for contar, é a coisa que eu mais uso. Dae uso o face e what's(WhatsApp), pra falar com meus amigos também e ver o que ta acontecendo, mas não sou muito ligado nisso não, fico mais online mesmo pra falar com o pessoal.

Nos relatos podemos notar que o facebook é o mais utilizado, mas também os jovens consomem as mídias Tradicionais através do celular.

Como aqui é longe da cidade a antena não pega direito os canais de televisão, ae quando eu quero eu vejo no celular mesmo porque é melhor, o ruim é que não tem como tu ver os canais fechados que passam, mas mesmo assim é mais vantagem. Mas olho só quando sei que vai dar um filme que eu gosto, já o rádio eu ouço mais, até pra saber das notícias da cidade e tal, porque as vezes a gente demora pra saber caso não fale com ninguém de lá da cidade. (...) Assim, se fosse escolher a que eu mais gosto ia dizer o face né, porque dá pra eu ver um monte de coisa tipo, foto, desenho, vídeo e falar com o pessoal, mas não dispenso o rádio, acho que ele ficaria em segundo lugar se fosse pra escolher. 
O uso do celular no meio rural

Às vezes não pega, ae eu fico só com o aparelho por ficar mesmo, mas não me importo muito até, eu tenho computador em casa só que a rede é pior, e fica complicado tu tentar falar com os amigos sem internet, sem ser pelo face, porque todo mundo tem face e se fala mais por ele, se eu não tiver como me comunicar com o pessoal vou ficar bem isolado e depois de um tempo é capaz até dos amigos esquecerem do cara, hoje em dia é assim tem que procurar pra ser procurado.

A Caixa Preta

Assim eu não me importo muito com o celular, não em questão de crédito e tal porque se e não tenho eu uso o da mãe até ela colocar crédito no meu, mas eu sempre carrego por causa das minhas coisas que tenho nele e pra usar internet. Mas é bom, eu gosto de usar a internet mais no campo, quando to lidando (trabalhando) com o gado ae é mais fácil eu levar o celular do que o computador, e me distraio nele o que faz com que o tempo passe mais rápido na lida. Tipo, com ou sem internet eu posso sempre me entreter com algum jogo, e se eu quiser falar com alguém troco mensagem mesmo. Até pedi de natal um melhor (mais moderno) ae quem sabe eu baixe outro jogos que os meus tão batidos já (nessa altura da entrevista os dois rimos e encerrei os questionamentos).

Ao encerrar a entrevista o jovem deixou o celular sobre a toalha de crochê que enfeitava a mesa de centro e deslocou-se aos fundos da casa onde se encontravam os demais 'homens da casa' para auxiliá-los no churrasco. Notou-se durante a entrevista a dispersão do mesmo com o aparelho, ele reconhecesse a importância do celular através das mídias como objeto de interação e reconhecimento na sociedade, porém prioriza no mesmo, serviços mais convencionais.

As respostas de Thiago condizem com 30\% dos pesquisados, que também mantem redes de relacionamento nas redes, reconhecem sua importância, mas não são colocadas como primordial elemento, em vista que preferem outras maneiras de interação ainda que não deixa as virtuais de lado, ou totalmente abandonada. 


\section{CONCLUSÃO}

Os conteúdos retratados na mídia digital em muitos casos se torna um refúgio da realidade para os jovens, pois, no espaço virtual, todos os adolescentes podem disfarçar melhor a ansiedade, a confusão, os medos e a alegria da passagem à vida adulta (ESTEFENON, 2009). As mídias passam a ser não só mais uma fonte de entretenimento e informações, mas sim com o avanço das novas ferramentas, verdadeiros canais sociais, onde se percebe uma comunidade conectada o dia inteiro, com os aparelhos na palma da mão e sempre ao seu alcance.

Algumas impressões e constatações ao final das abordagens apontaram para dados bastante peculiares na pesquisa. As abordagens nos mostram que os jovens da fronteira passam a utilizar mais os dispositivos móveis a fim de estar sempre interligados com os amigos e no meio digital construído pelos mesmos para torná-los mais próximos. Em relação ao consumo de mídia, nos aprofundamos na ferramenta mais utilizada por eles, o facebook. Alegam a alta usualidade devido as várias utilidades em um só local, podem manter conversas, visitas e conhecer pessoas através de seus perfis, compartilhar imagens, vídeos, notícias entre outras variedades de entretenimento e informação. Mas apesar de ser a mais acessada, o Twitter e youtube não são deixados de lados por usuários da rede, o Twitter serve como uma ferramenta de 'desabafo contínuo', e sua técnica apesar de não ser exclusiva do meio é melhor aplicada nele.

O YouTube mantém seus internautas pela comodidade em seus canais, e por ser exclusivamente uma rede de vídeos já ter cativado seu público fixo, que acompanha seus canais, vlogs ${ }^{1}$ e playlist ${ }^{2}$, além dos filmes disponibilizados nele. O que segundo os jovens é ótimo, pois podem ouvir e ver algumas mídias ao mesmo tempo, e não de maneira aleatória já que são eles que decidem o que vão ver e ouvir.

A surpresa maior na pesquisa não foi dentro das mídias estudadas, mas sim na 'substituição' de muitos dos serviços disponibilizados nestas por um aplicativo: o WhatsApp. Tal aplicativo utilizado exclusivamente para troca de

\footnotetext{
1 Vlog é a abreviação de videoblog (vídeo + blog), um tipo de blog em que os conteúdos predominantes são os vídeos. Fonte: http://www.significados.com.br/vlog/

2 Termo utilizado no meio da radiodifusão para se referir a uma determinada lista de canções, que podem ser tocadas em sequência ou embaralhadas. Fonte: http://dicionario. babylon.com/playlist/
} 
mensagens, ganha espaço entre os jovens, pois funciona no meio digital não causando nenhuma perda de crédito financeiro como acontece na troca de SMS. O mesmo ainda permite que nas ‘conversações' possam ser compartiIhados vídeos e imagens, sejam elas em grupo ou individuais entre duas ou mais pessoas.

Notamos, com este estudo, a grande inserção dos jovens da fronteira no meio digital através do celular, durante as observações e conversações muitos faziam uso do aparelho, mesmo em companhia de outras pessoas, trocavam mensagens e navegavam pela rede, sem que desviassem sua atenção ao que estava acontecendo em seu redor.

Por fim, se compreendeu que se constituiu uma nova realidade a partir desses dispositivos, em que se estabelecem relações e novas formas de estar junto físico ou virtualmente, onde os jovens se conhecem e se reconhecem através de opiniões e preferências veiculadas pela mídia. Isso demonstra que o espaço fronteiriço também se reconfigura a partir da inserção dos jovens nas mídias digitais. 


\section{REFERÊNCIAS}

ALMEIDA, Cristóvão, FEITOSA, Sara. Práticas solidárias e visibilidade juvenil: os processos educativos fomentando transformações. In.: ASQUIDAMINI, Fabiane e VIAL, Eloir Antonio. (Org.). Sustentabilidade eis a questão: juventudes, trabalho e economia. São Leopoldo: CEBI, 2010. p. 101-107

BACCEGA, Maria Aparecida. Comunicação e culturas do Consumo. São Paulo: Atlas, 2008.

CARNEIRO, Camilo; SEVILLA,Gabriela; AVILA, Róber. Faixa de fronteira do Rio Grande do Sul: economia, infraestrutura e gestão do território. Textos para Discussão FEE N 107. Porto Alegre, outubro de 2012.

EISENSTEIN, Evelyn; STEFENON, Susana Graciela Bruno. Geração Digital: riscos e benefícios das novas tecnologias para crianças e adolescentes. Rio de Janeiro: Vieira \& Lent, 2009.

ESCOSTEGUY, Ana C. Os Estudos Culturais. In: HOHLFELDT, A., MARTINO, L. C., FRANÇA, V. Teorias da Comunicação: conceitos, escolas e tendências. Petrópolis, RJ: Vozes, 2001.

. Cartografias dos estudos culturais: uma versão latino-americana. Belo Horizonte: Autêntica, 2004.

ESCOSTEGUY, Ana C; JACKS, Nilda. Comunicação e recepção. São Paulo: Hacker, 2005.

IBGE. Instituto Brasileiro de Geografia e Estatística. <http://cidades.ibge. gov.br/xtras/perfil.php?lang=\&codmun=431800\&search=rio-grande-do-sul|sao-borja >Acesso em 13 de ago. 2014.

JENKINS, Henry. Cultura da Convergência. São Paulo: Aleph, 2008.

RAMONET, Igmacio. Propagandas silenciosas: massas, televisão, cinema. Petrópoles,RJ: Vozes, 2002.

SANTAELLA, Lucia. Culturas e artes do pós-humano: da cultura das mídias à cibercultura. São Paulo: Paulus, 2003.

TELLES, André. Geração Digital: como planejar o seu marketing para 
uma geração que pesquisa no Google, se relaciona no Orkut, manda mensagens pelo celular, opina em Blogs, se comunica pelo MSN e assiste a vídeos no YouTube. São Paulo: Landscape, 2009.

VERZA, Fabiana. O uso do celular na adolescência e sua relação com a família e grupo de amigos. Porto Alegre: Faculdade de Psicologia da Pontifícia Universidade Católica do Rio Grande do Sul, 2008. 
JUVENTUDE E CELULAR: A BATALHA DAS MÍDIAS SOCIAIS NA FRONTEIRA

RECEBIDO EM:16/05/2015

APROVADO PARA PUBLICAÇÃO:02/07/2015 


\section{Resumo sobre autores:}

Cristovão Domingos Almeida Doutor em Comunicação e Informação pela UFRGS, mestre em Educação pela Unisinos, graduado em Relações Públicas pela Puc-Campinas e professor do curso de RP na Unipampa.

Anelice Belmonte Graduada em Relações Públicas com Ênfase em Produção Cultural pela Unipampa, graduanda em Publicidade e Propaganda pela mesma Instituição e bolsista FAPERGS.

Ronaldo Colvero Doutor e mestre em História, graduado em História e Estudos Sociais. É professor Adjunto na Unipampa e diretor do campus São Borja/Unipampa. 
